\title{
Epicardial adipose tissue and insulin resistance in patients with coronary artery disease with or without left ventricular dysfunction
}

\author{
Tessuto adiposo epicardico e insulino resistenza \\ in pazienti con cardiopatia ischemica cronica \\ con o senza disfunzione ventricolare sinistra
}

\author{
Samuele Baldasseroni, Alessandra Pratesi, Francesco Orso, Claudia Di Serio, \\ Alice Foschini, Andrea Giosafat Marella, Nadia Bartoli, Mauro Di Bari, Stefano Fumagalli, \\ Niccolò Marchionni, Francesca Tarantini
}

\begin{abstract}
Epicardial adipose tissue and insulin resistance in patients with coronary artery disease with or without left ventricular dysfunction. S. Baldasseroni, A. Pratesi, F. Orso, C. Di Serio, A. Foschini, A.G. Marella, N. Bartoli, M. Di Bari, S. Fumagalli, N. Marchionni, F. Tarantini.

Background. Epicardial adipose tissue (EAT) is a visceral fat that fulfills two important functions: lipid-storage and secretion of adipokines with pro-inflammatory and pro-atherogenic properties. It has been suggested that EAT may affect the pathogenesis of atherosclerosis and the clinical course of coronary artery disease (CAD). In patients with obesity, diabetes and metabolic syndrome, the epicardial adipose tissue is enlarged. Little is known about the role of EAT in left ventricular dysfunction. Aim of this study was to evaluate the ability of insulin resistance to predict EAT thickness in patients with significant CAD and systolic dysfunction.

Methods. We enrolled 114 subjects diagnosed with CAD by angiography. The majority underwent revascularization after an acute coronary syndrome. Patients were considered
\end{abstract}

\begin{abstract}
affected by significant left ventricular dysfunction when EF was $\leq 40 \%$. Three indexes of insulin resistance, the HOMA IR index, the insulin sensitivity QUICKI index, and the novel

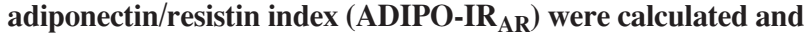
correlated to EAT thickness. Epicardial fat was measured by echocardiography according to standardized methods.

Results. Subjects with diabetes and with a history of hypercholesterolemia had thicker EAT compared to controls. Potassium levels and all three indexes of insulin resistance were the best independent predictors of EAT in the study population as a whole and in the subset of patients with left ventricular dysfunction. In the latter group the novel ADIPO-IR ${ }_{\mathrm{AR}}$ index displayed the strongest predictivity.

Conclusion. Insulin resistance is an independent predictor of EAT thickness in patients affected by CAD, also in the presence of significant left ventricular dysfunction

Keywords: epicardial fat, insulin resistance, coronary artery disease, adipokine, left ventricular dysfunction.
\end{abstract}

Monaldi Arch Chest Dis 2013; 80: 170-176.

Department of Clinical and Experimental Medicine, Geriatric Cardiology and Medicine Unit, University of Florence; Azienda Ospedaliero-Universitaria Careggi, Florence (Italy).

Corresponding author: Samuele Baldasseroni MD, PhD; Department of Heart and Vessels; Geriatric Cardiology and Medicine Unit; University of Florence and Azienda Ospedaliero-Universitaria Careggi; Viale Morgagni 85, I-50134 Florence, Italy; Phone: +390554271472; Fax:+390554271469; E-mail address:pesine@libero.it

\section{Introduction}

Epicardial adipose tissue (EAT) is a visceral fat located between the outer layer of the myocardium and the visceral pericardium. It is mainly concentrated in the atrioventricular and interventricular grooves, along the major branches of the coronary arteries, and, to a minor extent, around the atria, over the free wall of the right ventricle and the apex of the left ventricle [1]. In physiologic conditions, EAT fulfills two important distinct functions: lipidstorage and secretion of hormones and peptides. Indeed, EAT may be considered an endocrine organ, capable of producing and releasing several bioactive adipokines, as well as pro-inflammatory and proatherogenic cytokines [2]. However, EAT also pro- duces anti-inflammatory and anti-atherogenic adipokines [3]. It is well known that EAT shares with the myocardium the same microcirculation and, given its proximity to the heart muscle and to the adventitia of the coronary arteries, it is believed to affect the pathogenesis of atherosclerosis and the clinical course of coronary artery disease (CAD) [4].

In healthy people, epicardial fat has been measured with different radiological tools. Iacobellis et al. [5] using standardized echocardiography found that thickness of epicardial fat, measured at any site over the right ventricular free wall, varied between 1.8 and $16.5 \mathrm{~mm}$. EAT can be assessed also by Multidetector Computerized Tomography and by Magnetic Resonance Imaging (MRI) which, despite a lower spatial resolution and higher costs, is 
considered the gold standard [6]. EAT assessed by echocardiography correlates well with the extent of visceral fat evaluated by MRI, but it is only weakly related to body mass index or waist circumference $[6,7]$.

In the general population, EAT correlates negatively with markers of insulin sensitivity [8] and positively with markers of insulin resistance [7]; in addition, it is significantly more abundant in subjects with metabolic syndrome $[6,7]$.

As mentioned above, emerging evidence suggests that EAT could play a role as risk factor for the development of CAD, its severity and vulnerability of atherosclerotic plaques $[9,10]$. However, little is known about the role of epicardial fat in left ventricular dysfunction. Studies on healthy subjects have demonstrated that more abundant EAT correlates significantly with greater left ventricular mass [11]. In a study evaluating epicardial fat volume (EFV) with CT scan, subjects with left ventricular dysfunction had significantly lower EFV than subjects with preserved function [12]. Even when EAT was assessed volumetrically by cardiovascular MRI, subjects with ventricular dysfunction showed lower amount of EAT compared to healthy controls [13].

Aims of this study were: 1 ) to evaluate three different indexes of insulin resistance for their ability to predict EAT thickness in patients with CAD and 2 ) to test their predictive power in a subgroup of patients with left ventricular dysfunction.

\section{Methods}

Study subjects: 114 patients referred to the Cardiac and Diabetic Outpatient Clinic of the Geriatric Cardiology and Medicine Unit of Careggi Academic Hospital (Florence, Italy) were enrolled, provided that they met the following inclusion criteria: willing to give written informed consent, previously diagnosed with CAD by angiography (with at least one $\geq 75 \%$ stenosis of a major epicardial branch), clinically stable (Canadian Cardiovascular Society Angina score $\leq 1$ ) with no hospitalization for worsening HF or need for an increased dosage of the current cardiac drug therapy, during the last two months. The study was approved by an institutional review committee, according to the Helsinki declaration.

Clinical and instrumental data: patients underwent a thorough clinical history, including reporting of symptoms needed to define New York Heart Association (NYHA) class, physical examination with measurement of height and weight to calculate body mass index (BMI) and waist circumference, 12-lead electrocardiogram (ECG), and 6-minute walking test (6-WT) according to the Guyatt's protocol [14]. A standard echocardiographic study was carried out following the American Society of Echocardiography recommendations [15]. Heart failure (HF) was considered to be overt in the presence of positive European Society of Cardiology criteria [16], associated with a Boston score $\geq 5$ [17], and significant left ventricular systolic dysfunction was defined as ejection fraction (EF) $\leq 40 \%$. Type 2 diabetes mellitus was diagnosed according to ADA-WHO criteria [18].
Biochemical data: venous blood samples were drawn in the fasting state to measure glycaemia, insulinemia, glycated hemoglobin (HbAlc) - determined by high liquid pressure chromatography method (Menarini Diagnostics, Florence, Italy; upper normal limit 5.9\%), hemoglobin, electrolytes, uric acid, serum albumin, total and fractional cholesterol, and triglycerides. Glomerular filtration rate was estimated according to the Modification of Diet in Renal Disease (MDRD) Study method (eGFR).

Adipokines and indexes of insulin resistance: circulating plasma resistin and total adiponectin were determined, in duplicate, by ELISA (Linco Research, Missouri, USA). Three insulin resistance indexes were calculated, the HOMA IR index [19], the insulin sensitivity QUICKI index [20], and the novel adiponectin/resistin index (ADIPO-IR ${ }_{\mathrm{AR}}$ ) [21] defined as follows:

$\log _{10}\left(\mathrm{I}_{0} * \mathrm{G}_{0}\right)+\left[\log _{10}\left(\mathrm{I}_{0} * \mathrm{G}_{0}\right) \log _{10}\left(\mathrm{R}_{0} / \mathrm{A}_{0}\right)\right.$ where $I_{0}$ is fasting serum insulin, $G_{0}$ fasting plasma glucose, $\mathrm{R}_{0}$ fasting resistin level and $\mathrm{A}_{0}$ total fasting adiponectin level.

Measurement of EAT thickness: each subject underwent two-dimensional transthoracic echocardiography (Acuson Sequoia 512 ${ }^{\circledR}$ Ultrasound with 3 MHz transducer; Siemens, Mountain View, California, USA); standard parasternal and apical views were obtained in the left lateral decubitus position. Epicardial fat was identified as the echo-free space between the linear echo-dense parietal pericardium and the right ventricular epicardium and its thickness was measured perpendicularly on the free wall of the right ventricle, at end-systole, in three cardiac cycles, according to Jacobellis method [5].

Statistical analysis: data were analyzed using SPSS $®$ software (version 18); results are expressed as mean $\pm \mathrm{SD}$ and as percentage for continuous or categorical variables, respectively. Statistical comparisons were carried out with Student t-test or with chi-square test when necessary. Correlations were analysed with Pearson R-test for variables with normal distribution and with Spearman R-test for those with not normal distribution. Variables significantly associated with EAT thickness at univariate analysis, were entered in three multivariable stepwise backward linear regression models, one for each predefined index of insulin resistance (HOMA, QUICKI, and ADIPO IR $\mathrm{AR}_{\mathrm{AR}}$ indexes). Among variables with independent predictive value but similar clinical significance, only one was introduced in the model, to avoid co-linearity; parameters comprised in the mathematical formula of insulin resistance indexes were excluded. Multivariable models were tested in the study population as a whole and in the subgroup of patients with left ventricular systolic dysfunction. A $p$ value less than 0.05 was considered statistically significant.

\section{Results}

Clinical characteristics of the study population are reported in Table 1. Fifty percent of the subjects had type 2 diabetes mellitus; $15 \%$ was in NYHA class III-IV. Mean EAT thickness was $7.8 \mathrm{~mm}$. Renal function and biohumoral variables were within normal, or near normal, range (Table 1). 
Table 1. - Clinical, echocardiographic and biohumoral characteristics of the study population: continuous variables are expressed as mean \pm SD and categorical variables as number (percentage)

\begin{tabular}{|c|c|c|}
\hline & $\mathrm{n}=\mathbf{1 1 4}$ & $\begin{array}{l}\text { agreement with } 50 \% \text { of the population being at } \\
\text { fected by diabetes. }\end{array}$ \\
\hline Age, yrs & $66.7 \pm 10.7$ & Subjects with diabetes (Figure 1) and with a his- \\
\hline Female gender & $16(14.0)$ & tory of hypercholesterolemia (Figure 2) had signifi- \\
\hline BMI $\left(\mathrm{Kg} / \mathrm{m}^{2}\right)$ & $27.3 \pm 4.1$ & pared to non-diabetics and non-hypercholes- \\
\hline Waist circumference $(\mathrm{cm})$ & $100.9 \pm 11.8$ & terolemic control subjects. \\
\hline
\end{tabular}

Previous myocardial infarction 93 (81.6)

Previous angina $50(43.9)$

\begin{tabular}{l} 
Previous stroke \\
\hline
\end{tabular}

\begin{tabular}{ll}
\hline Hypertension & $80(70.2)$
\end{tabular}

\begin{tabular}{ll}
\hline Hypercholesterolemia & $83(72.8)$ \\
\hline
\end{tabular}

Smokers $59(51.6)$

Previous CABG 33 (29.8)

Previous PCI $90(78.9)$

Left main coronary artery pathology $12(10.5)$

Three vessels disease 43 (37.7)

Atrial fibrillation $20(17.5)$

Diabetes $57(50.0)$

COPD $12(10.5)$

PAD $19(16.6)$

Distance at 6-WT (m) $436.8 \pm 170.2$

NYHA class III-IV 17 (14.9)

Echocardiographic variables

Septal thickness (mm) $\quad 9.8 \pm 2.1$

Posterior wall thickness (mm) $10.2 \pm 3.2$

$\mathrm{LV}$ end systolic volume $\left(\mathrm{ml} / \mathrm{m}^{2}\right) \quad 82.0 \pm 28.7$

$\mathrm{LV}$ end diastolic diameter $\left(\mathrm{ml} / \mathrm{m}^{2}\right) \quad 47.9 \pm 26.6$

Ejection fraction $(\%) \quad 44.9 \pm 15.2$

\begin{tabular}{ll}
\hline IVRT (msec) & $90.2 \pm 23.9$
\end{tabular}

E/A ratio $1.2 \pm 1.0$

Tdec (msec) 245.0 277.3

Myocardial mass $\left(\mathrm{gr} / \mathrm{m}^{2}\right) \quad 126.3 \pm 36.5$

EAT thickness (mm) $\quad 7.8 \pm 3.1$

Biohumoral variables

eGFR $\left(\mathrm{ml} / \mathrm{min} / 1.73 \mathrm{~m}^{2}\right) \quad 74.0 \pm 24.8$

Hemoglobin $(\mathrm{g} / \mathrm{dl}) \quad 13.6 \pm 1.5$

Potassium (meq/l) $4.3 \pm 0.6$

Sodium (meq/l) $139.7 \pm 10.1$

Uric acid $(\mathrm{mg} / \mathrm{dl}) \quad 6.6 \pm 5.6$

Albumin (gr/l) $3.8 \pm 0.5$

Total cholesterol (mg/dl) $169.3 \pm 37.9$

HDL cholesterol (mg/dl) $44.8 \pm 12.6$

LDL cholesterol (mg/dl) $\quad 96.2 \pm 30.6$

6-WT, 6-minute walking test; BMI, body mass index; CABG, coronary artery by-pass graft; COPD, chronic obstructive pulmonary disease; EAT, epicardial adipose tissue; IVRT, isovolumic relaxation time; LV, left ventricular; NYHA, New York Heart Association; PAD, peripheral artery disease; PCI, percutaneous coronary intervention; Tdec, deceleration time.
The glycometabolic profile of the study population is summarized in Table 2. Mean values of insulinemia, glycated hemoglobin, plasma adipokines concentrations and insulin resistance indexes are in agreement with $50 \%$ of the population being afcted by diabetes.

Sujects with diabete cantly higher values of EAT thickness when comterolemic control subjects.

Table 2. - Glycometabolic profile of the study population

\begin{tabular}{lc}
\hline & $\mathbf{n}=\mathbf{1 1 4}$ \\
\hline Glycemia $(\mathrm{mg} / \mathrm{dl})$ & $122.1 \pm 48.4$ \\
\hline Insulinemia $(\mathrm{pmol} / \mathrm{l})$ & $19.4 \pm 30.1$ \\
\hline Hb1AC $(\%)$ & $6.8 \pm 1.3$ \\
\hline Resistin level $(\mathrm{ng} / \mathrm{ml})$ & $10.7 \pm 5.7$ \\
\hline Total adiponectin level $(\mathrm{ng} / \mathrm{ml})$ & $8.9 \pm 6.7$ \\
\hline HOMA index & $5.7 \pm 7.9$ \\
\hline QUICK index & $0.32 \pm 0.04$ \\
\hline ADIPO-IR & $3.6 \pm 1.4$ \\
\hline
\end{tabular}

ADIPO-IR $_{\mathrm{AR}}$, Adipose tissue Insulin Resistance adiponectin/ resistin index; Hb1AC, glycated hemoglobin; HOMA-IR, HOmeostatic Model Assessment- Insulin Resistance; QUICKI, QUantitative Insulin sensitivity ChecK Index.

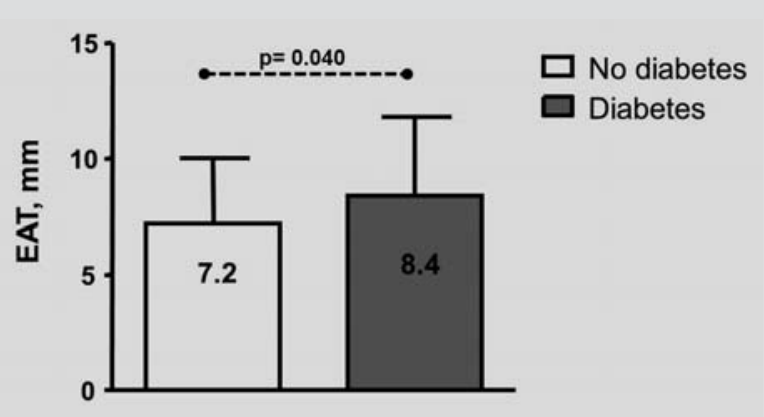

Figure 1. - Difference of EAT thickness (mm) between diabetic and non-diabetic patients.

EAT, epicardial adipose tissue

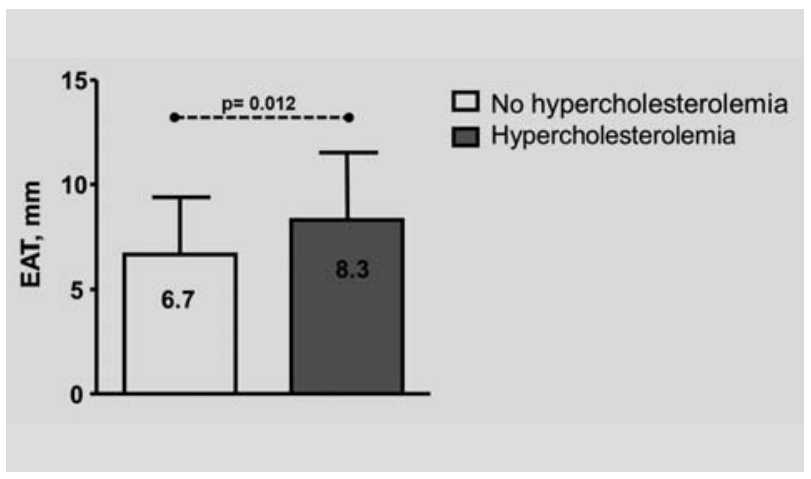

Figure 2. - Difference of EAT thickness (mm) between hypercholesterolemic and non-hypercholesterolemic patients.

EAT, epicardial adipose tissue 
Univariate analysis: clinical, echocardiographic and biohumoral variables that showed a significant association with EAT thickness are reported in Table 3. Insulinemia, adiponectinemia and all three indexes of insulin resistance showed a significant association with EAT, with adiponectinemia and QUICKI index displaying an inverse correlation (Table 4).

Table 3. - Association between clinical, echocardiographic and biohumoral variables and EAT thickness

\begin{tabular}{lcc}
\hline BMI & $\mathbf{R}$ & $\mathbf{p}$ \\
\hline Waist circumference & 0.31 & 0.001 \\
\hline 6-WT & 0.34 & $<0.001$ \\
\hline Potassium & -0.26 & 0.005 \\
\hline Septal thickness & 0.28 & 0.005 \\
\hline Tdec & 0.24 & 0.011 \\
\hline $6-W 7$ & 0.20 & 0.041 \\
\hline
\end{tabular}

6-WT, 6-minute walking test; BMI, body mass index; Tdec, deceleration time.

Table 4. - Association between glycometabolic variables and EAT thickness

\begin{tabular}{|c|c|c|}
\hline & $\mathbf{R}$ & $\mathbf{p}$ \\
\hline Insulinemia & 0.38 & $<0.001$ \\
\hline Total adiponectin & -0.19 & 0.023 \\
\hline HOMA index & 0.26 & 0.008 \\
\hline QUICKI index & -0.33 & 0.001 \\
\hline ADIPO-IR ${ }_{\mathrm{AR}}$ index & 0.28 & 0.006 \\
\hline
\end{tabular}

ADIPO-IR ${ }_{\mathrm{AR}}$, Adipose tissue Insulin Resistance adiponectin/ resistin index; HOMA-IR, HOmeostatic Model AssessmentInsulin Resistance; QUICKI, QUantitative Insulin sensitivity ChecK Index.

Multivariable analysis: the multivariable regression models for the population as a whole (Panel A) and for patients with left ventricular dysfunction (Panel B) are reported in Table 5. At multivariate analysis, all three indexes of insulin resistance maintained their independent predictive value in both populations. When we considered the study population as a whole (Panel A), plasma potassium level was an independent predictor of EAT thickness, whereas in the subset of subjects with left ventricular dysfunction (Panel B), potassium maintained its predictive power only in Model 3; deceleration time of mitral E wave (Tdec) was an independent predictor of EAT thickness in Models 1 and 2.

\section{Discussion}

In our population, the mean value of EAT thickness was $7.8 \mathrm{~mm}$, significantly higher than that found by Eroglu et al. [22] who established a value of $5.2 \mathrm{~mm}$ as the cut-off of epicardial fat thickness for association with CAD. Nevertheless, if we consider their subgroup of patients with significant coronary artery disease (two and three-vessel disease), which is more similar to our study population, the two values are almost identical.

However, unlike other reports [23], we did not find an association between epicardial fat thickness and severity of CAD defined by the number of coronary arteries affected by at least $75 \%$ stenosis or by the number of site of percutaneous/grafting revascularization. This result confirms that the role of EAT as a marker of CAD severity is everything but established and, probably, is greatly influenced by the method used to define disease severity itself [23]. Nonetheless, it is highly likely that epicardial fat may influence the evolution of coronary atherosclerosis, through the production of many pro-atherogenic cytokines able to modify plaque composition, vulnerability and stability [9, 32].

We found that diabetic patients had a higher EAT thickness compared to those without diabetes. This data is in accordance with several literature reports which also show that increased EAT thickness in diabetic subjects is related to the presence of higher visceral adiposity and body mass index, and longer waist circumference [24].

We also clearly demonstrated that, independently from the type of index we used to define the glycometabolic profile, insulin resistance and serum potassium level were the strongest, independent predictors of EAT thickness, irrespective to the presence of diabetes. This result is not surprising if we consider that kalemia is strictly linked to peripheral insulin sensibility, since insulin stimulates $\mathrm{K}^{+}$cellular uptake in skeletal muscles and other tissues, including liver and adipose tissue [25].

The association of EAT thickness with insulin resistance has been recognized already in obesity and type 2 diabetes [8]; in addition, the power of EAT to predict the presence of metabolic syndrome has been well established [7] in a large observational study of 246 patients, undergoing standardized echocardiography, in which waist circumference and HOMA-IR index were the best predictors of epicardial fat thickness.

The correlation between insulin resistance and epicardial fat in patients with CAD, with or without myocardial revascularization, has been less studied. Ahn et al. [26], in a large Asian population affected by CAD in which the severity of disease was established by coronary angiography, found that HOMA score displayed only a weak association with EAT; conversely, a good correlation was found with visceral adiposity. However, in that study patients with prior myocardial revascularization, heart failure, cardiomyopathy and acute myocardial infarction were excluded, and the HOMA score was tested only in non-diabetic patients. In our study, three different indexes of insulin resistance were tested in a Caucasian population with CAD, almost entirely revascularized and with a large percentage of type 2 diabetic patients. Insulin resistance showed a strong correlation with EAT, independently from the type of index we used to define it. Moreover, this is the first time that the new $A D I P O-I_{A R}$ index was 
Table 5. - Multivariable stepwise backward linear regression models (EAT thickness as continuous dependent variable) Panel A (whole study population)

\begin{tabular}{|c|c|c|c|}
\hline & $\begin{array}{l}\text { Model 1 } \\
R^{2}=0.25\end{array}$ & $\begin{array}{l}\text { Model } 2 \\
R^{2}=0.29\end{array}$ & $\begin{array}{l}\text { Model } 3 \\
R^{2}=0.28\end{array}$ \\
\hline & Beta; p value & Beta; $p$ value & Beta; $p$ value \\
\hline Age & $0.06 ; p=0.682$ & $0.16 ; p=0.164$ & $0.03 ; p=0.843$ \\
\hline Gender & $-0.02 ; p=0.866$ & $0.04 ; p=0.736$ & $0.03 ; p=0.840$ \\
\hline Waist circumference & $0.06 ; p=0.652$ & $0.01 ; p=0.952$ & $0.05 ; p=0.787$ \\
\hline Type 2 diabetes & $0.09 ; p=0.466$ & $0.03 ; p=0.805$ & $0.18 ; p=0.169$ \\
\hline Hypercholesterolemia & $0.08 ; p=0.514$ & $0.04 ; p=0.751$ & $0.09 ; p=0.436$ \\
\hline Potassium & $0.42 ; p<0.001$ & $0.40 ; p<0.001$ & $0.35 ; p=0.005$ \\
\hline 6-WT & $-0.15 ; p=0.211$ & $-0.08 ; p=0.566$ & $-0.24 ; p=0.047$ \\
\hline Septal thickness & $0.12 ; p=0.311$ & $0.10 ; p=0.374$ & $0.12 ; p=0.313$ \\
\hline Tdec & $0.16 ; p=0.177$ & $0.13 ; p=0.226$ & $0.14 ; p=0.244$ \\
\hline HOMA index & $0.26 ; p=0.021$ & & \\
\hline QUICKI index & & $-0.34 ; p=0.002$ & \\
\hline ADIPO-IR ${ }_{A R}$ index & & & $0.28 ; p=0.016$ \\
\hline
\end{tabular}

6-WT, 6-minute walking test; ADIPO-IR ${ }_{\mathrm{AR}}$, Adipose tissue Insulin Resistance adiponectin/resistin index; HOMA-IR, HOmeostatic Model Assessment- Insulin Resistance; QUICKI, QUantitative Insulin sensitivity ChecK Index; Tdec, deceleration time.

Table 5. - Multivariable stepwise backward linear regression models (EAT thickness as continuous dependent variable) Panel B (patients with left ventricular systolic dysfunction, EF $\leq 40 \%$ )

\begin{tabular}{|c|c|c|c|}
\hline & $\begin{array}{l}\text { Model } 1 \\
R^{2}=0.32\end{array}$ & $\begin{array}{l}\text { Model } 2 \\
\mathrm{R}^{2}=0.38\end{array}$ & $\begin{array}{l}\text { Model } 3 \\
R^{2}=0.35\end{array}$ \\
\hline & Beta; $p$ value & Beta; $p$ value & Beta; $p$ value \\
\hline Age & $-0.21 ; p=0.680$ & $-0.18 ; \mathrm{p}=0.738$ & $0.29 ; p=0.241$ \\
\hline Gender & $-0.25 ; p=0.342$ & $-0.27 ; p=0.291$ & $-0.34 ; \mathrm{p}=0.188$ \\
\hline Waist circumf. & $-0.23 ; \mathrm{p}=0.323$ & $-0.14 ; \mathrm{p}=0.597$ & $-0.28 ; \mathrm{p}=0.184$ \\
\hline Type 2 diabetes & $0.18 ; p=0.508$ & $0.20 ; p=0.439$ & $0.03 ; p=0.911$ \\
\hline Hypercholesterolemia & $-0.18 ; \mathrm{p}=0.505$ & $-0.23 ; \mathrm{p}=0.429$ & $0.05 ; \mathrm{p}=0.834$ \\
\hline Potassium & $0.08 ; p=0.848$ & $0.07 ; p=870$ & $0.61 ; p=0.016$ \\
\hline 6-WT & $-0.28 ; \mathrm{p}=0.353$ & $-0.27 \mathrm{p}=0.295$ & $-0.04 ; p=0.966$ \\
\hline Septal thickness & $-0.36 ; p=0.123$ & $-0.20 ; p=0.374$ & $-0.03 ; \mathrm{p}=0.913$ \\
\hline Tdec & $0.47 ; p=0.061$ & $0.51 ; p=0.038$ & $0.24 ; p=0.294$ \\
\hline HOMA index & $0.47 ; p=0.060$ & & \\
\hline QUICKI index & & $-0.54 ; p=0.028$ & \\
\hline
\end{tabular}

\section{ADIPO IR AR $_{\text {index }}$}

6-WT, 6-minute walking test; ADIPO-IR $\mathrm{AR}$, Adipose tissue Insulin Resistance adiponectin/resistin index; HOMA-IR, HOmeostatic Model Assessment- Insulin Resistance; QUICKI, QUantitative Insulin sensitivity ChecK Index; Tdec, deceleration time. 
demonstrated to predict epicardial fat thickness. In our opinion, this index is quite attractive because hypo-adiponectinemia and hyper-resistinemia have been associated with the glycometabolic profile and, recently, also with CAD [27]; therefore, this index summarizes well the contribution of both adipokines to the insulin resistance biological profile.

Another critical finding of our study is that insulin resistance still remains the main contributing factor to EAT thickness, even in patients with left ventricular dysfunction. Previous data have demonstrated that impaired insulin sensibility is related to both systolic [28] and diastolic [29] left ventricular dysfunction, and several molecular mechanisms may be invoked to explain this association. In fact, hyperinsulinemia may contribute to the sympathetic nervous system hyperactivity that unfavorably impacts the progression towards left ventricular dysfunction [30]; moreover, it has been clearly proved that insulin resistance potentiates the effect of angiotensin II on cardiomyocyte hypertrophy and collagen production, leading to myocardial hypertrophy and fibrosis which are responsible for the unfavorable cardiac remodeling observed in ischemic heart disease [31]. Based on our findings, an additional hypothesis may be generated to explain the link between insulin resistance, EAT thickness and left ventricular dysfunction: the detrimental effect of insulin resistance on myocardial cells could be mediated by EAT through a harmful, paracrine secretory profile. This hypothesis seems to be supported by the recent work of Greulich et al. [32]: these Authors clearly demonstrated that epicardial fat tissue can have a direct influence on cardiomyocyte metabolism and function. They showed that adult rat cardiomyocytes, incubated with conditioned media obtained from EAT biopsies of patients with type 2 diabeteshave a significant reduction in sarcomere shortening, cytosolic calcium-flux, and insulin-mediated phosphorylation of target proteins, with a consequent myocardial dysfunction. This is the first demonstration of a direct, active pathophysiological contribution of epicardial fat to myocardial dysfunction.

In conclusion, insulin resistance, measured with different standardized indexes, independently predicts EAT thickness in patients affected by CAD. Moreover, its predictive power also persists in patients with left ventricular dysfunction. In subjects with CAD, the association of EAT with increased body mass index and waist circumference is mediated by the presence of reduced insulin sensibility, a feature of the metabolic syndrome.

Study limitations. The study presents all limitations of a cross-sectional design. Sample size is limited, although the population is quite homogeneous in terms of management of CAD and left ventricular dysfunction, because it was enrolled by a single center. Evaluation of EAT thickness was carried out by an expert cardiologist, but not in a blinded manner.

\section{Riassunto}

Razionale. Il grasso epicardico (GE) è un grasso viscerale che compie due principali funzioni: di deposito di grasso e di secrezione di adipochine con proprietà pro-infiammatorie e pro-aterogene. È sta- to suggerito che il GE possa contribuire alla patogenesi dell' aterosclerosi e influenzare la storia clinica della coronaropatia. Nei pazienti con obesità, diabete mellito di tipo 2 e sindrome metabolica il GE è maggiormente rappresentato. Poco si sa sul ruolo del GE nella disfunzione del ventricolo sinistro. Scopo di questo studio è valutare la capacità dell' insulino-resistenza di predire lo spessore del GE nei pazienti con coronaropatia e disfunzione sistolica del ventricolo sinistro.

Materiali e metodi. Abbiamo arruolato $114 \mathrm{pa}$ zienti con diagnosi di coronaropatia effettuata mediante angiografia, la maggior parte dei quali sottoposti a rivascolarizzazione dopo una sindrome coronarica acuta. La disfunzione ventricolare sinistra è stata considerata significativa per frazione di eiezione $\leq 40 \%$. Sono stati calcolati tre indici di insulino-resistenza: HOMA-IR index, QUICKI, e il nuovo adiponectin/resistin index (ADIPO-IRAR); questi successivamente sono stati correlati con lo spessore del GE. Il GE è stato misurato tramite ecocardiografia secondo i criteri di Iacobellis.

Risultati. I soggetti con diabete mellito di tipo 2 e storia di ipercolesterolemia avevano un GE più spesso rispetto ai controlli. I livelli di potassiemia e tutti e tre gli indici di insulino-resistenza sono risultati essere $i$ migliori predittori indipendenti dello spessore del GE sia nella popolazione totale che nei pazienti con disfunzione ventricolare sinistra. In quest' ultimo gruppo il nuovo ADIPO-IRAR index ha mostrato il maggior valore predittivo.

Conclusioni. L'insulino-resistenza è un predittore indipendente dello spessore del GE nei pazienti affetti da coronaropatia, anche in presenza di una significativa disfunzione del ventricolo sinistro.

Parole chiave: grasso epicardico, insulino resistenza, cardiopatia ischemica cronica, adipochine, disfunzione ventricolare sinistra.

\section{ACRONYMOS}

ADIPO-IR $\mathbf{R}_{\mathrm{AR}}=$ Adipose tissue Insulin Resistance adiponectin/ resistin index

BMI $=$ Body Mass index

CAD $=$ Coronary artery Disease

EAT $=$ Epicardial Adipos Tissue

ECG = electrocardiogram

$\mathbf{E F}=$ Ejection Fraction

EFV = Epicardial Fat Volume

ELISA = Enzyme-Linked Immuno-Sorbent Assay

$\mathbf{H F}=$ Heart failure

HOMA-IR = HOmeostatic Model Assessment- Insulin Resistance MRI = Magnetic Resonance Imaging

NYHA = New York Heart Association

QUICKI = QUantitative Insulin sensitivity ChecK Index

\section{References}

1. Iozzo P. Myocardial perivascular and epicardial fat. Diabetes Care 2011; 34: 371-379.

2. Mazurek T, Zhang L, Zalewski A, et al. Human epicardial adipose tissue is a source of inflammatory mediators. Circulation 2003; 108: 2460-6.

3. Baker AR, Silva NF, Quinn DW, et al. Human epicardial adipose tissue expresses a pathogenic profile of adipocytokines in patients with cardiovascular disease. Cardiovasc Diabetol 2006; 5: 1. 
4. Iacobellis G, Pistilli D, Gucciardo M, et al. Adiponectin expression in human epicardial adipose tissue in vivo is lower in patients with coronary artery disease. Cytokine 2005; 29: 251-5.

5. Iacobellis G, Gioia CR, Di Vito M, et al. Epicardial adipose tissue and intracoronary adrenomedullin levels in coronary artery disease. Horm Metab Res 2009; 41: 855-60.

6. Mahabadi AA, Massaro JM, Rosito GA, et al. Association of pericardial fat, intrathoracic fat, and visceral abdominal fat with cardiovascular disease burden: The Framingham Heart Study. Eur Heart J 2009; 30: 850-6.

7. Iacobellis G, Willens HJ. Echocardiographic Epicardial Fat: A Review of Research and Clinical Applications. $J$ Am Soc Echocardiogr 2009; 22: 1311-9.

8. Iacobellis G, Assael F, Ribaudo MC, et al. Epicardial fat from echocardiography: a new method for visceral adipose tissue prediction. Obes Res 2003; 11: 304-10.

9. Iacobellis G, Willens HJ, Barbaro G, Sharma AM. Threshold values of high risk echocardiographic epicardial fat thickness. Obesity 2008; 16: 887-92.

10. Iacobellis G, Leonetti F. Epicardial adipose tissue and insulin resistance in obese subjects. J Clin Endocrinol Metab 2005; 90: 6300-2.

11. Park JS, Choi SY, Zheng M, et al. Epicardial adipose tissue thickness is a predictor for plaque vulnerability in patients with significant coronary artery disease. Atherosclerosis 2013; 226: 134-9.

12. Jacobellis G, Corradi D, Sharma AM. Epicardial adipose tissue: anatomic, biomolecular and clinical relationships with the heart. Nat Clin Pratic Cardiovasc 2005; 2: 536-543.

13. Khawaja T, Greer C, Chokshi A, et al. Epicardial fat volume in patients with left ventricular systolic dysfunction. Am J Cardiol 2011; 108: 397-401.

14. Doesch C, Haghi D, Flüchter S, et al. Epicardial adipose tissue in patients with heart failure. J Cardiovasc Magn Reson 2010; 12: 40.

15. Campeau L. The Canadian Cardiovascular Society grading of angina pectoris revisited 30 years later. Can J Cardiol 2002; 18: 371-9.

16. Guyatt GH, Sullivan MJ, Thompson PJ, et al. The 6minute walk: a new measure of exercise capacity in patients with chronic heart failure. Can Med Assoc J 1985; 132: 919-23.

17. Picard MH, Adams D, Bierig SM, et al. American Society of Echocardiography recommendations for quality echocardiography laboratory operations. J Am Soc Echocardiogr 2011; 24: 1-10.

18. Swedberg K, Cleland J, Dargie H, et al. Guidelines for the diagnosis and treatment of chronic heart failure: executive summary [update 2005]: The Task Force for the Diagnosis and Treatment of Chronic Heart Failure of the European Society of Cardiology. Eur Heart J 2005; 26: 1115-1140.

19. Di Bari M, Pozzi C, Cavallini MC, et al. The diagnosis of heart failure in the community. Comparative validation of four sets of criteria in unselected older adults: the ICARe Dicomano Study. J Am Coll Cardiol 2004; 44: 1601-8.

20. American Diabetes Association. Diagnosis and Classification of Diabetes Mellitus. Diabetes Care 2009; 33 : 62-69.

21. Levey AS, Bosch JP, Lewis JB, Greene T, Rogers N, Roth D. A more accurate method to estimate glomerular filtration rate from serum creatinine: a new prediction equation. Modification of Diet in Renal Disease Study Group. Ann Intern Med 1999; 130: 461-470.

22. Matthews DR, Hosker JP, Rudenski AS, et al. Homeostasis model assessment: insulin resistance and beta-cell function from fasting plasma glucose and insulin concentrations in man. Diabetologia 1985; 7: 412-419.

23. Katz A, Nambi SS, Mather K, et al. Quantitative insulin sensitivity check index: a simple, accurate method for assessing insulin sensitivity in humans. J Clin Endocrinol Metab 2000; 85: 2402-2410.
24. Lau CH, Muniandy S. Novel adiponectin-resistin (AR) and insulin resistance (IRAR) indexes are useful integrated diagnostic biomarkers for insulin resistance, type 2 diabetes and metabolic syndrome: a case control study. Cardiovasc Diabetol 2011; 10: 1-18.

25. Eroglu S, Sade LE, Yildirir A, et al. Epicardial adipose tissue thickness by echocardiography is a marker for the presence and severity of coronary artery disease. Nutr Metab Cardiovasc Dis 2009; 19: 211-7.

26. Chaowalit N, Somers VK, Pellikka PA, et al. Subepicardial adipose tissue and the presence and severity of coronary artery disease. Atherosclerosis 2006; 186: 354-9.

27. Alexopoulos N, McLean DS, Janik M, Arepalli CD, Stillman AE, Raggi P. Epicardial adipose tissue and coronary artery plaque characteristics. Atherosclerosis. 2010; 210: 150-4.

28. Gorter PM, Van Lindert AS, De Vos AM, et al. Quantification of epicardial and pericoronary fat using cardiac computed tomography; reproducibility and relation with obesity and metabolic syndrome inpatients suspected of coronary artery disease. Atherosclerosis 2008; 197: 896-903.

29. Ross R, Leger L, Morris D, et al. Quantification of adipose tissue by MRI: relationship with anthropometric variables. J Appl Physiol 1992; 72: 787-95.

30. Wasada T. Adenosine Triphosphate-Sensitive Potassium (KATp) Channel Activity is Coupled with Insulin Resistance. Internal Medicine 2002; 41: 84-90.

31. Fehlman M, Freychet P. Insulin and glucagon stimulation of $(\mathrm{Na}+\mathrm{K}+)$-ATPase transport activity in isolated rat hepatocytes. J Biol Chem 1981; 256: 7449-7453.

32. Gourley DRH, Bethea MD. Insulin effect on adipose tissue sodium and potassium. Proc Soc Exp Biol Med 1964; 115: 821-823.

33. Iacobellis G, Leonetti F. Epicardial adipose tissue and insulin resistance in obese subjects. J Clin Endocrinol Metab 2005; 90: 6300-2.

34. Wang CP, Hsu HL, Hung WC, et al. Increased epicardial adipose tissue (EAT) volume in type 2 diabetes mellitus and association with metabolic syndrome and severity of coronary atherosclerosis. Clin Endocrinol 2009; 70: 876-82.

35. Ahn SG, Lim HS, Joe DY, et al. Relationship of epicardial adipose tissue by echocardiography to coronary artery disease. Heart 2008; 94: 1-6.

36. Shimabukuro M, Hirata Y, Tabata M, et al. Epicardial Adipose Tissue Volume and Adipocytokine Imbalance Are Strongly Linked to Human Coronary Atherosclerosis. Arterioscler Thromb Vasc Biol 2013; 33:,1077-84.

37. Ärnlöv J, Lind L, Zethelius B et al. Several factors associated with the insulin resistance syndrome are predictors of left ventricular systolic dysfunction in a male population after 20 years of follow-up. Am Heart $J$ 2001; 142: 720-724.

38 Ärnlöv J, Lind L, Sundström J, Andren B, Vessby B, Lithell $\mathrm{H}$. Insulin resistance, dietary fat intake and blood pressure predict left ventricular diastolic dysfunction twenty years later. Nutr Metab Cardiovasc Dis 2005; 15: 242-9.

39. Anderson EA, Hoffman RP, Balon TW, Sinkey CA, Mark AL. Hyperinsulinemia produces both sympathetic neural activation and vasodilation in normal humans. $J$ Clin Invest 1991; 87: 2246-2252.

40. Bell DS. Heart failure: the frequent, forgotten, and often fatal complication of diabetes. Diabetes Care 2003; 26: 2433-2441.

41. Sutton MG, Sharpe N. Left ventricular remodeling after myocardial infarction: pathophysiology and therapy. Circulation 2000; 101: 2981-2988.

42. Greulich S, Maxhera B, Vandenplas G, et al. Secretory products from epicardial adipose tissue of patients with type 2 diabetes mellitus induce cardiomyocyte dysfunction. Circulation 2012; 126: 2324-34. 